\title{
Neoadjuvant chemoradiotherapy followed by esophagectomy vs. surgery alone in the treatment of resectable esophageal squamous cell carcinoma
}

\author{
YOSHINORI FUJIWARA ${ }^{1}$, REIGETSU YOSHIKAWA ${ }^{2}$, NORIHIKO KAMIKONYA ${ }^{3}$, TSUYOSHI NAKAYAMA ${ }^{1}$, \\ KOTARO KITANI ${ }^{1}$, MASANORI TSUJIE ${ }^{1}$, MASAO YUKAWA ${ }^{1}$, JOHJI HARA ${ }^{1}$, \\ TAKEHIRA YAMAMURA ${ }^{4}$ and MASATOSHI INOUE ${ }^{1}$
}

\author{
${ }^{1}$ Department of Digestive Surgery, Nara Hospital, Kinki University School of Medicine, Ikoma, Nara 630-0293; \\ ${ }^{2}$ Department of Surgery, Kanzaki Hospital, Amagasaki, Hyogo 661-0967; Departments of ${ }^{3}$ Radiology \\ and ${ }^{4}$ Surgery, Hyogo College of Medicine, Nishinomiya, Hyogo 663-8501, Japan
}

Received November 19, 2012; Accepted April 29, 2013

DOI: $10.3892 / \mathrm{mco} .2013 .128$

\begin{abstract}
In order to improve the survival of esophageal cancer patients, a trimodality therapy consisting of esophagectomy in combination with neoadjuvant chemoradiotherapy (CRT) has been developed. In this study, we evaluated whether neoadjuvant CRT improved the outcomes of patients with resectable esophageal squamous cell carcinoma (ESCC) compared to surgery alone. Eighty-eight patients with resectable ESCC were treated with either neoadjuvant CRT followed by surgical resection (Group A, n=52), or surgery alone (Group B, $\mathrm{n}=36)$. CRT consisted of 5-fluorouracil $\left(5-\mathrm{FU}, 500 \mathrm{mg} / \mathrm{m}^{2}\right.$ on days 1-5) and cisplatin (CDDP, $10-20 \mathrm{mg} / \mathrm{kg}$ body weight on days 1-5), repeated after 3 weeks. Survival analysis was performed using the log-rank test with the Kaplan-Meier method. The clinical response of the primary tumor and metastatic nodes was $80.8 \%$. The postoperative complications profile was similar between the two groups, except for anastomotic leakage. The median survival time (MST) was not reached in Group A and was 27.4 months in Group B. The estimated 5-year overall survival (OS) rate was $50.3 \%$ in Group A and 39.9\% in Group B $(\mathrm{P}=0.134)$. As regards stage II/III disease, Group A exhibited a better disease-free survival (DFS) compared to Group B (5-year DFS: $57.2 \%$ in Group A vs. $31.4 \%$ in Group $\mathrm{B} ; \mathrm{P}=0.025)$. Simultaneous locoregional and distant recurrences were more common in the surgery alone group (Group B, $\mathrm{P}=0.047$ ). Neoadjuvant CRT with 5-FU and CDDP did not contribute to a better prognosis in patients with resectable ESCC. However, it may be beneficial for patients with stage II/III disease.
\end{abstract}

Correspondence to: Dr Yoshinori Fujiwara, Department of Digestive Surgery, Nara Hospital, Kinki University School of Medicine, 1248-1 Otoda-cho, Ikoma, Nara 630-0293, Japan

E-mail: yyfujiwara@nifty.com

Key words: esophageal cancer, trimodality therapy, survival

\section{Introduction}

Esophageal cancer is the eighth most common type of cancer worldwide, with an estimated 481,645 new cases in 2008, and the sixth most common cause of cancer-related mortality, with 406,533 deaths in 2008 (1). Esophageal squamous cell carcinomas (ESCCs) are more common in Asian countries, including Japan, compared to Western countries, where adenocarcinomas in the lower third of the esophagus are commonly encountered. According to the National Cancer Center data base (2), 11,746 Japanese patients succumbed to esophageal cancer in 2008, which was equivalent to $3.26 \%$ of the total deaths from malignant neoplasms in Japan.

Esophageal cancer is highly aggressive and has a poor prognosis due to early metastasis to the lymph nodes, as well as metastasis to distant organs (3-5). Surgery has been considered as the mainstay of treatment for patients with confirmed, locoregionally confined esophageal carcinoma. However, until a decade ago the 3- or 5-year survival rate was $<30 \%$ worldwide, according to previous studies using several different approaches (6,7-10). In Japan, the survival rate has shown improvement over the last two decades since three-field lymphadenectomy was introduced in the early 1980s by Isono et al (11) and Ando et al (12), a modality that is now widely used. In comparison, en bloc esophagectomy, also known as extensive esophagectomy, is performed in Western countries (13-15). However, even with extensive radical surgery involving the esophagus, locoregional or distant recurrences have been observed in $8-32 \%$ of patients (16-25). The estimated 5 -year survival rates for esophageal cancer treated with curative intent were $34-53 \%(11,26-28)$. To improve the survival of locoregional esophageal carcinoma, multimodal therapy comprising chemotherapy and/or radiotherapy in combination with radical surgery has been developed. An approach involving neoadjuvant chemoradiotherapy (CRT) followed by esophagectomy, known as trimodality therapy $(29,30)$, is mainly used. It offers the potential advantages of tumor downstaging, reduced dissemination of malignant cells during surgery and prevention of micrometastasis. Nine randomized 
trials were conducted on patients with confirmed locoregionally confined esophageal cancer who received preoperative CRT compared to surgery alone (30-38). Two of these studies demonstrated an improved outcome, despite the limited patient sample $(30,38)$, whereas the remaining studies showed no survival benefits in the trimodality therapy group. Therefore, the benefits of preoperative CRT remain controversial. In addition, there is no ongoing or planned randomized study that is related to preoperative CRT for ESCC in Japan. Since 1996 , preoperative CRT using 5-fluorouracil (5-FU) and cisplatin (CDDP) combined with radical surgery has been employed for the treatment of advanced esophageal cancers, with reported increased resectability, reduced incidence of local recurrence and distant metastasis and a more favorable prognosis for CRT responders (39). Additionally, we have reported that preoperative CRT in UICC stage II/III (non-T4) ESCC contributed to tumor shrinkage, leading to higher resectability and longer patient survival (40).

In the present retrospective study on patients with resectable esophageal cancer who underwent extensive radical esophagectomy, we investigated whether increased survival benefits were obtained from neoadjuvant CRT plus surgery, compared to surgery alone.

\section{Patients and methods}

Patients. Patients with histologically confirmed ESCC who had not undergone treatment previously were considered eligible for inclusion in the present study. Endoscopy and CT scan and/or endoscopic ultrasound examination were mandatory for determining clinical stage (II, III or IV disease) in patients with resectable disease according to the UICC TNM Classification of Malignant Tumors (41). The eligibility criteria for the present study were as follows: age $<80$ years, adequate organ function (white blood cell count $\geq 3,500$, hemoglobin $\geq 10 \mathrm{~g} / \mathrm{dl}$, aspartate aminotransferase/alanine aminotransferase $\leq 2 x$ upper limit of normal, platelet count $\geq 100,000 / \mathrm{mm}^{3}$, serum creatinine $\leq 1.3 \mathrm{mg} / \mathrm{dl}$ ) and a performance status (Eastern Cooperative Oncology Group) of $<2$ at the time of admission. Eighty-eight patients were enrolled in our study. Of these, 52 patients received preoperative CRT followed by esophagectomy (Group A) and 36 patients received esophagectomy alone (Group B) between August, 1997 and June, 2011 at the Departments of Surgery of Hyogo College of Medicine (Nishinomiya, Japan) and Nara Hospital, Kinki University School of Medicine (Ikoma, Japan). Informed consent was obtained from the patients.

Neoadjuvant CRT followed by esophagectomy. Neoadjuvant radiotherapy (1 fraction/day) was performed for 5 days per week (Monday to Friday) using a linear accelerator (Mevatron KD2; Toshiba, Kawasaki, Japan). Patients received 20 fractions of $2 \mathrm{~Gy}$ up to a total radiation dose of $40 \mathrm{~Gy}$. The radiation field encompassed the primary tumor volume (as defined by endoscopy, esophagography and CT scans) with a $3-\mathrm{cm}$ margin in each cephalad and caudal direction and 4-cm horizontal margins. If lymph node metastasis was detected using $\mathrm{CT}$, the radiation field was extended to include the primary tumor and the metastatic lesions. Concurrent chemotherapy consisted of 5 -FU ( $500 \mathrm{mg} / \mathrm{m}^{2} /$ day $)$ administration by a $120-\mathrm{h}$ continuous intravenous infusion starting on day 1 and CDDP (15-20 mg/day) by a 2-hour intravenous infusion on days 1-5 and repeated after 3 weeks. Esophagectomy was planned for 4-7 weeks following completion of CRT. The majority of patients underwent thoracotomy, laparotomy and cervicotomy in order to perform esophagectomy with two- or three-field lymphadenectomy and gastroesophageal anastomosis at the left side of the neck. Radical resection (R0) was defined as the removal of the macroscopic tumors, no evidence of distant metastasis, absence of a microscopic residual tumor, free resection margins and lymphadenectomy extending beyond the involved nodes. Resection was defined as non-radical when microscopic (R1) or macroscopic (R2) residual tumor was identified according to the TNM criteria (41).

Evaluation of response after CRT. The effects of CRT on the primary tumor and the metastatic nodes were assessed at 2-3 weeks after the completion of radiotherapy, using chest CT scanning, barium esophagography and/or upper gastrointestinal endoscopy and/or ultrasonography. The response to therapy was defined according to the criteria of the Japanese Society of Esophageal Disease (42) as follows: i) complete response (CR), defined as $100 \%$ regression of cancer; ii) partial response (PR), defined as $>50 \%$ regression of the primary tumor and metastatic nodes; iii) progressive disease (PD), defined as an increase of $25 \%$ in the size of the primary tumor or metastatic nodes or the appearance of new lesions; and iv) no change (NC) defined as a decrease of $<50 \%$ in the size of the primary tumor and metastatic nodes and no evidence of tumor progression. Toxicities were classified according to the National Cancer Institute Common Terminology Criteria (NCI CTC) guidelines (43).

Esophagectomy (surgery alone). Esophagectomy was performed through a small thoracotomy $(\sim 10 \mathrm{~cm})$ using thoracoscopy-assisted esophagectomy with two- or three-field lymphadenectomy including the upper mediastinum. The reconstruction was routinely performed using the retrosternal root and gastroesophageal anastomosis at the left side of the neck. The degree of radical resections (R) was similarly assessed according to the TNM system (41).

Locoregional failure and distant metastasis. After the first recurrence was noted, any additional recurrence identified within 1 month was considered to have occurred simultaneously. Locoregional recurrences were defined as anastomotic recurrences or recurrences that occurred either in the mediastinum or the upper abdomen at the site of previous esophageal resection and nodal clearance. Distant recurrences were defined as hematogenous or other types (in the pleura or peritoneum). Cervical, celiac axis and para-aortic nodal metastases were classified as distant metastasis according to TNM system (41).

Statistical analysis. The differences between the two groups (A and B) in terms of patient characteristics, postoperative complications and recurrence patterns were evaluated using the Fisher's exact test. Overall survival (OS) was defined as the time from the date of initial treatment to patient death or to the date of the last available information on the vital status. Disease-free survival (DFS) was defined as the 
length of time after treatment during which no cancer was detected. Differences between the cumulative survival rates of the patient groups were calculated using the log-rank test for comparisons of the Kaplan-Meier survival curves. $\mathrm{P}<0.05$ was considered to indicate a statistically significant difference. Univariate analyses were used to assess patient characteristics and other prognostic factors. The Cox proportional hazards model was used to determine differences in survival between the two treatment groups and subgroups. Statistical analyses were performed using STATISTICA software, version 06J (StatSoft, Tulsa, OK, USA) and SPSS statistics, version 16 (SPSS Japan Inc., Tokyo, Japan).

\section{Results}

Patient characteristics. The patient characteristics are summarized in Table I. Eighty-eight patients were evaluated in this study, including 52 patients in Group A (neoadjuvant CRT+surgery) and 36 patients in Group B (surgery alone). The tumors were histologically confirmed as ESCCs. No statistical differences were observed in age, male/female ratio, location of primary tumor, lymph node metastasis or clinical stage. As regards the depth of tumor invasion, there was a tendency for deeper invasion in Group A compared to that in Group B patients $(\mathrm{P}<0.001)$. R0 resection was performed in 42 patients in Group A and the patients in Group B. Ten patients in Group A underwent R1 resection. Patients with positive cervical and/or celiac nodes (M1a, M1b) were classified as clinical stage IV. One patient in Group A had a double cancer of the esophagus and lower pharynx. She received radiotherapy to the neck preoperatively, at a total dose of $60 \mathrm{~Gy}$, in order to preserve the pharynx and larynx.

Response to neoadjuvant CRT and toxicity. The clinical response of the primary tumor and the metastatic nodes is provided in Table II. Lymph node metastasis was observed in 18 patients by CT scans or upper gastrointestinal ultrasonography. The patients with NC and PD for metastatic nodes had celiac or neck lymph node metastasis, respectively. At the radiologists' suggestion, these fields were excluded from the primary radiation field to avoid postoperative complications. The clinical response $(\mathrm{CR}+\mathrm{PR})$ to neoadjuvant CRT for the primary tumor and the metastatic nodes was 86.5 and $44.4 \%$, respectively. The collective clinical response of the primary tumor and metastatic nodes was $80.8 \%$. Major toxicology profiles were summarized in medical records.

Leukocytopenia exceeding grade 3 was observed in $21.1 \%$ of patients, grade $1 / 2$ general fatigue was observed in $30.8 \%$, grade $1 / 2$ nausea in $28.9 \%$, grade $2 / 3$ loss of appetite in $23.1 \%$ and grade 2 liver dysfunction in $3.8 \%$ of the patients, respectively. There was no reported CRT-related mortality.

Surgery and postoperative complications. Eighty-five patients (51 patients in Group A and 34 in Group B) underwent esophagectomy via right thoracotomy with two- or three-field lymphadenectomy in both groups. One patient in Group A underwent lower esophagectomy with proximal subtotal gastrectomy via left thoracotomy and jejunal reconstruction was performed. Furthermore, one patient in Group A received a total esophagectomy with laryngectomy. Additionally,
Table I. Clinicopathological characteristics.

\begin{tabular}{|c|c|c|c|}
\hline Variables & Group A & Group B & P-value \\
\hline \multicolumn{4}{|l|}{ Age (years) } \\
\hline Mean & 60.11 & 64.6 & NS \\
\hline \multicolumn{4}{|l|}{ Gender } \\
\hline Male & 42 & 32 & NS \\
\hline Female & 10 & 4 & \\
\hline \multicolumn{4}{|c|}{ Location of primary tumor } \\
\hline Upper esophagus & 7 & 2 & NS \\
\hline Middle esophagus & 29 & 13 & \\
\hline Lower esophagus & 16 & 19 & \\
\hline Abdominal & 0 & 2 & \\
\hline \multicolumn{4}{|c|}{ Depth of tumor invasion } \\
\hline $\mathrm{T} 1 \mathrm{~b}$ & 0 & 1 & $<0.001$ \\
\hline $\mathrm{T} 2$ & 2 & 14 & \\
\hline T3 & 34 & 21 & \\
\hline $\mathrm{T} 4$ & 16 & 0 & \\
\hline \multicolumn{4}{|l|}{ N-classification } \\
\hline No & 34 & 17 & NS \\
\hline N1 & 11 & 19 & \\
\hline M1a & 2 & 0 & \\
\hline M1b & 5 & 0 & \\
\hline \multicolumn{4}{|l|}{ Clinical stage } \\
\hline II & 27 & 22 & NS \\
\hline III & 18 & 14 & \\
\hline IV & 7 & 0 & \\
\hline
\end{tabular}

NS, non-significant.

one patient in Group A received ileocecal replacement since he had previously undergone gastrectomy for early gastric cancer. Two patients in Group B underwent lower esophagectomy with proximal subtotal gastrectomy via left thoracotomy and jejunal reconstruction was performed. Postoperative complications from medical records are summarized in Table III. Leakage following esophagogastrostomy was observed in 4 patients (7.5\%) in Group A, a lower incidence compared to Group B $(\mathrm{P}=0.027)$. Two patients in Group $\mathrm{A}$ underwent additional surgery to restore the continuity of the alimentary tract. One patient received jejunal interposition between the gastric tube and the neck of the esophagus and another patient received skin flap transplantation of the latissimus dorsi muscle.

Pathological response of the primary tumor. Sixteen out of the 52 patients that received neoadjuvant CRT $(30.8 \%)$ showed no residual tumor in the resected esophagus, which was compatible with pathological CR.

Recurrence pattern. Comparisons of incidence and type of disease recurrence between the two treatment groups are provided in Table IV. The incidence of simultaneous locoregional and distant recurrence was significantly higher in Group B compared to that in Group A ( $\mathrm{P}=0.0474)$. 
Table II. Effects of preoperative CRT on the primary tumor and the metastatic nodes.

Clinical response rate

\begin{tabular}{lccc} 
Response & Primary tumor & Metastatic nodes & (Primary tumor and metastatic nodes) \\
\hline $\mathrm{CR}$ & 16 & 4 & 14 \\
$\mathrm{PR}$ & 29 & 4 & 28 \\
$\mathrm{NC}$ & 7 & 8 & 8 \\
$\mathrm{PD}$ & 0 & 2 & 2 \\
Response rate & $86.5 \%$ & $44.4 \%$ & $80.8 \%$ \\
\hline
\end{tabular}

CRT, chemoradiotherapy; CR, complete response; PR, partial response; NC, no change; PD, progressive disease.
Table III. Postoperative complications in the two groups.

\begin{tabular}{lccc}
\hline & Group A & Group B & P-value \\
\hline Blood loss (ml), mean & 528 & 684 & NS \\
Respiratory failure (\%) & 5.7 & 13.8 & NS \\
Anastomotic leakage (\%) & 7.5 & 25 & 0.027 \\
Recurrent nerve palsy (\%) & 3.8 & 5.25 & NS \\
30-day mortality (\%) & 0 & 2.78 & NS \\
Hospital death (\%) & 1.9 & 8.3 & NS \\
\hline
\end{tabular}

DFS and OS. The median follow-up period was 44.8 months in Group A and 24.6 months in Group B. The OS for Groups A and $\mathrm{B}$, including hospital deaths, is shown in Fig. 1. The median survival time (MST) was not achieved in Group A and was 27.4 months in Group B. The estimated 3- and 5-year OS rates were 52.7 and $50.3 \%$, respectively, in Group A and 39.9 and $39.9 \%$, respectively, in Group B. There was no significant difference between the two groups $(\mathrm{P}=0.134)$. The DFS in the two groups is shown in Fig. 2. The MST was 30.97 months in Group A and 13.37 months in Group B. The estimated 3- and 5-year DFS rates were 49.4 and 49.4\%, respectively, in Group A and 37.7 and $37.4 \%$, respectively, in Group B. Group A exhibited a tendency for a higher DFS rate compared to Group B, although there was no significant difference between the two groups $(\mathrm{P}=0.092)$. In the subgroup analysis of the patients with stage II/III disease, Group A exhibited a significantly improved OS rate compared to Group B (5-year OS, 59\% for Group A vs. 39.9\% for Group B, P=0.043). Similarly, a higher DFS rate was observed in Group A compared to Group B (5-year DFS, 57.2\% for Group A vs. 31.4\% for Group B, $\mathrm{P}=0.025)$.

Subgroup analysis. The results of the subgroup analysis for OS and DFS according to clinical stage, lymph node status, tumor depth of invasion, tumor location and resectability of stage II/III patients are shown in Table V. Patients with N0 tumors that received neoadjuvant CRT (Group A) had a significantly prolonged DFS compared to patients with N1 tumors and Group B patients. As regards OS, Group A exhibited a significantly prolonged survival rate and patients with N0 tumors showed a tendency for improved survival $(\mathrm{P}=0.057)$. Subgroup analysis regarding DFS is shown in

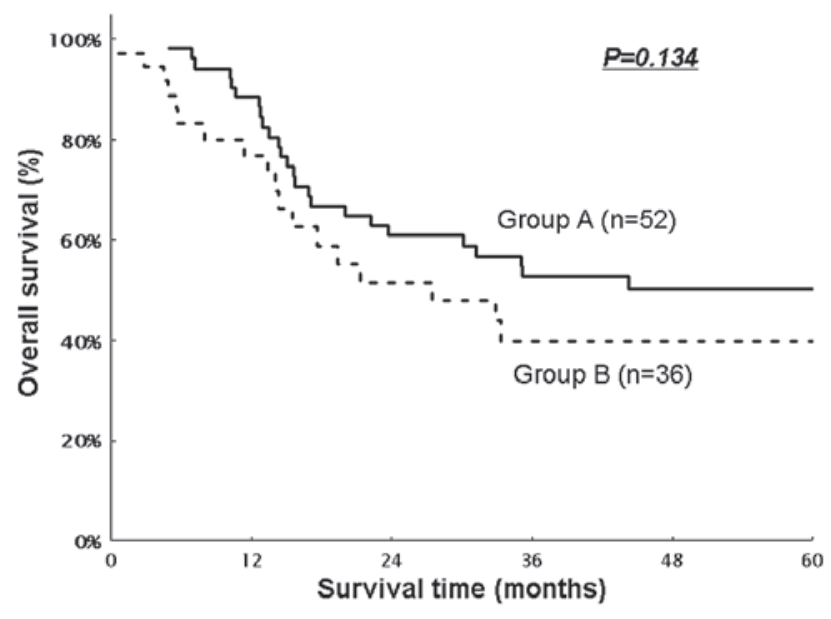

Figure 1. Comparison of overall survival between the neoadjuvant chemoradiotherapy (CRT) (Group A) and surgery alone (Group B) groups in stage II-IVa esophageal cancer patients.

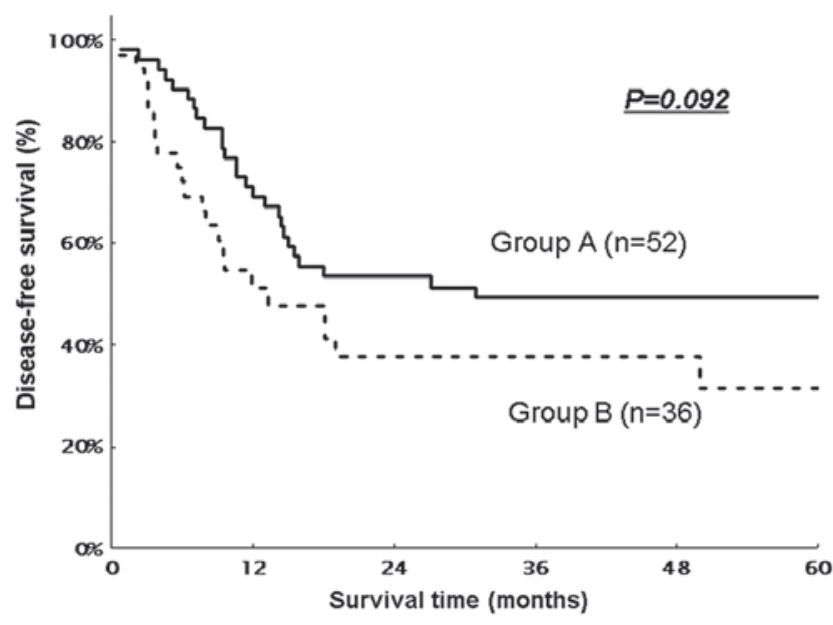

Figure 2. Comparison of disease-free survival between the neoadjuvant chemoradiotherapy (CRT) (Group A) and surgery alone (Group B) groups in stage II-IVa esophageal cancer patients.

Fig. 3. Patients with tumors located in the upper esophagus and tumors $\geq 5 \mathrm{~cm}$ in length exhibited a higher survival rate in Group A compared to Group B [hazard ratio (HR), 0.312 and $0.136-0.712$, respectively, for tumor location, HR, 0.254 and 0.071-0.907, respectively, for tumor length]. 
Table IV. Site of recurrence in 88 esophageal squamous cell carcinoma patients.

\begin{tabular}{|c|c|c|c|}
\hline Site & $\begin{array}{l}\text { Group A } \\
\text { No. }(\%)\end{array}$ & $\begin{array}{l}\text { Group B } \\
\text { No. }(\%)\end{array}$ & P-value \\
\hline Locoregional failure & $4 / 52(7.69)$ & $5 / 36(13.9)$ & NS \\
\hline Distant metastasis & $15 / 52(28.8)$ & 7/36 (19.4) & NS \\
\hline Local and distant simultaneously & $2 / 52(3.85)$ & $6 / 36(16.7)$ & 0.0474 \\
\hline
\end{tabular}

NS, not significant.

Table V. Univariate analysis of survival for stage II/III esophageal cancer patients.

\begin{tabular}{|c|c|c|c|c|c|}
\hline & & Disease-free survival & & Overall survival & \\
\hline Variables & No. & Hazard ratio $(95 \% \mathrm{CI})$ & P-value & Hazard ratio $(95 \% \mathrm{CI})$ & P-value \\
\hline CRT+surgery vs. surgery alone & $45 / 36$ & $0.488(0.263-0.905)$ & $0.023^{\mathrm{a}}$ & $0.516(0.269-0.989)$ & $0.046^{\mathrm{a}}$ \\
\hline Men vs. women & $68 / 13$ & $0.600(0.235-1.530)$ & 0.285 & $0.723(0.282-1.858)$ & 0.501 \\
\hline Age $(70>$ vs. $\geq 70)$ (years) & $20 / 61$ & $0.792(0.429-1.463)$ & 0.456 & $1.120(0.580-2.163)$ & 0.735 \\
\hline Clinical N0 vs. N1 & $51 / 30$ & $0.452(0.245-0.836)$ & $0.011^{\mathrm{a}}$ & $0.532(0.278-1.018)$ & 0.057 \\
\hline $\begin{array}{l}\text { b'Tumor location } \\
\text { (upper vs. lower) }\end{array}$ & $47 / 34$ & $1.208(0.652-2.239)$ & 0.548 & $1.316(0.688-2.514)$ & 0.406 \\
\hline $\begin{array}{l}\text { Tumor length } \\
\geq 5 \text { vs. }<5(\mathrm{~cm})\end{array}$ & $48 / 33$ & $1.197(0.638-2.262)$ & 0.579 & $1.546(0.766-3.040)$ & 0.229 \\
\hline
\end{tabular}

${ }^{\text {aS }}$ Statistically significant; ${ }^{\mathrm{b}}$ upper, tumor located above the bifurcation and mid-esophagus; lower, tumor located in the lower and abdominal esophagus. CRT, chemoradiotherapy; CI, confidence interval.

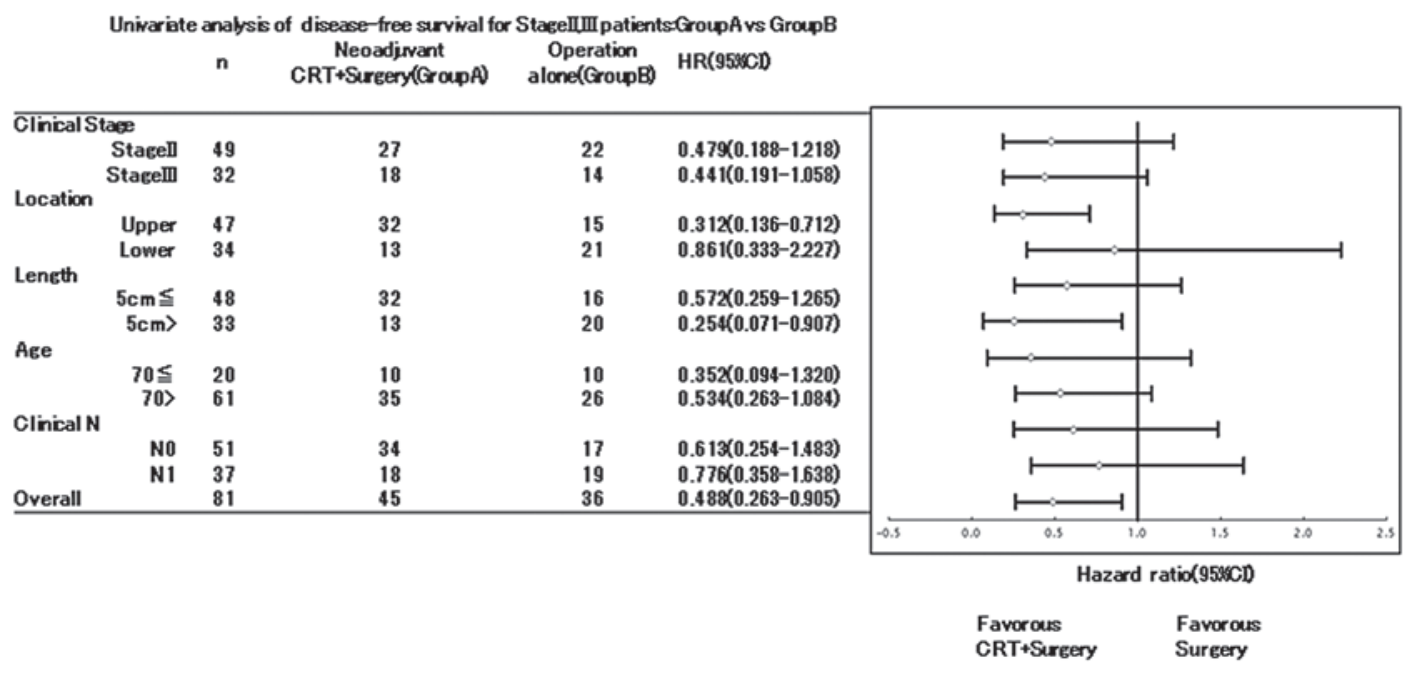

Figure 3. Univariate analysis of disease-free survival between Groups A and B in stage II/III esophageal cancer patients.

\section{Discussion}

In this retrospective study, we demonstrated that neoadjuvant CRT with 5-FU and CDDP conferred an increased survival benefit on patients with resectable stage II/III esophageal cancer, compared to surgery alone. As regards preoperative CRT, we have already shown that CRT in stage II/II (non-T4) patients contributed to tumor shrinkage, leading to higher resectability and longer survival (40). In this retrospective study, we only evaluated patients with resectable tumors, including T4 patients downstaged by neoadjuvant CRT. As shown in Table II, the clinical response rate for the primary tumor and the metastatic nodes following CRT exceeded $80 \%$. Therefore, neoadjuvant CRT proved to be effective for stage II/III esophageal cancer patients. Over the last few decades, surgical techniques and perioperative management, as well as the overall prognosis of 
esophageal cancer patients undergoing surgical resection, have significantly improved $(13,26,44)$. In Japan, three-field lymph node dissection is currently considered acceptable as a standard therapy for advanced esophageal SCC. However, the survival benefit of three-field lymph node dissection remains controversial (45-47). There have been no randomized phase III trials on two- or three-field lymph node dissection for ESCC in Japan. At present, we omit the procedure of neck lymph node dissection when there is no lymph node enlargement detected on preoperative CT scans. Our data demonstrated that the 5-year OS rate for surgery alone in stage II/III patients was $39.9 \%$, whereas the current survival rates of pathological stage IIA, IIB and III patients, classified according to UICC criteria, are reported to be $51.5,34.0$ and $19.8 \%$, respectively, according to the comprehensive registry of esophageal cancer in Japan (48). CRT for esophageal cancer has been developed mainly in the United States, since an RTOG study revealed that clinical benefits from CRT were superior to those from radiotherapy alone in the patients with localized carcinoma of the esophagus $(49,50)$. There have been two contradictory reports on stage II/III patients regarding the comparison of trimodality therapy compared to surgery alone $(33,38)$. Tepper et al $(38)$ evaluated patients in a neoadjuvant CRT group and demonstrated a survival advantage compared to surgery alone, supporting trimodality therapy as a standard of care for the patients with stage IIa-III esophageal cancer; however, this trial included a limited number of patients and the 5-year survival rate was significantly lower (39\% in the trimodality group vs. $10 \%$ in the surgery only group) (38). However, Apinop et al failed to demonstrate a clinical advantage due to trimodality therapy compared to surgery alone in 69 patients with stage IIb-III ESCC. This study also included a limited patient sample and the 5-year survival rate was low (24\% in the trimodality group vs. $10 \%$ in the surgery alone group) (33). Furthermore, neither study addressed the details of operative procedures, which may be different in Japan regarding lymph node dissection. Therefore, it is difficult to assess the efficacy of trimodality therapy in the same dimension. Burmeister et al (37) reported that trimodality therapy improved DFS, unlike OS, in patients with stage I-III ESCC, excluding adenocarcinoma (HR: 0.47 and 0.25-0.86, respectively) (37). This subset analysis has encouraged us to continue trimodality therapy for ESCC in Japan. We also reported an improved prognosis, especially for patients with tumors located higher and $<5 \mathrm{~cm}$ in diameter. However, the efficacy of CRT using our current regime may not suffice for tumors $>5 \mathrm{~cm}$ in diameter.

As regards the pattern of recurrence following surgical resection, we demonstrated a more frequent simultaneous locoregional and distant recurrence in patients after surgery alone. Neoadjuvant CRT has been reported to control tumor micrometastasis and to inhibit locoregional and distant metastasis (51). Locoregional recurrence and distant metastasis after radical esophagectomy with two- or three-field lymph node dissection have been found to vary from 11.3 to $32.6 \%$ and the incidence of simultaneous locoregional recurrence and distant metastasis has been reported to range from 1.1 to $13.9 \%$ (19-25). The major complications following esophagectomy with radical lymph node dissection were anastomotic leakage, recurrent nerve palsy and respiratory complications. Previous Japanese studies have indicated hospital mortality in $2.2-12.3 \%$ of the patients who underwent two- or three-field lymph node dissection, anastomotic leakage in $11-39 \%$, recurrent nerve palsy in $9-76 \%$ and respiratory complications in $8-32 \%(26,27,52,53)$. The incidence of postoperative complications after surgery alone in our study were in accordance with these data. Even when CRT was administered in combination with esophagectomy with extended lymph node dissection, the incidence of postoperative complications did not increase in our study. In Japan, neoadjuvant chemotherapy (CDDP plus 5-FU) followed by esophagectomy is currently considered the standard treatment for stage II/III esophageal cancer, although this was considered disputable by previous randomized studies (54-56). We strongly recommend that the the efficacy of CRT is objectively evaluated in Japan by additional JCOG studies.

In conclusion, treatment with neoadjuvant CRT consisting of 5-FU and CDDP did not contribute to a better prognosis in patients with resectable ESCC. However, it may be beneficial for patients with stage II/III disease. Additional large prospective randomized controlled trials involving preoperative CRT are required to elucidate whether this treatment may improve the prognosis of ESCC patients.

\section{References}

1. GLOBOCAN 2008, All Cancers (excluding non-melanoma skin cancer) Incidence and Mortality Worldwide. Available: http:// globocan.iarc.fr/factsheets/cancers/all.asp. Accessed August 26, 2012.

2. Cancer Statistics in Japan-2011. Available: http://ganjoho.jp/public/ statistics/backnumber/2011_jp.html. Accessed August 26, 2012.

3. Goseki N, Koike M and Yoshida M: Histopathologic characteristics of early stage esophageal carcinoma. A comparative study with gastric carcinoma. Cancer 69: 1088-1093, 1992.

4. Roth JA and Putnam JB Jr: Surgery for cancer of the esophagus. Semin Oncol 21: 453-461, 1994.

5. Sugimachi K, Inokuchi K, Kuwano H, Kai H, Okamura T and Okudaira Y: Patterns of recurrence after curative resection for carcinoma of the thoracic part of the esophagus. Surg Gynecol Obstet 157: 537-540, 1983.

6. Karl RC, Schreiber R, Boulware D, Baker S and Coppola D: Factors affecting morbidity, mortality, and survival in patients undergoing Ivor Lewis esophagogastrectomy. Ann Surg 231: 635-643, 2000.

7. Orringer MB, Marshall B and Iannettoni MD: Transhiatal esophagectomy: clinical experience and refinements. Ann Surg 230: 392-403, 1999.

8. Chu KM, Law SY, Fok M and Wong J: A prospective randomized comparison of transhiatal and transthoracic resection for lower-third esophageal carcinoma. Am J Surg 174: 320-324, 1997.

9. Lieberman MD, Shriver CD, Bleckner S and Burt M: Carcinoma of the esophagus. Prognostic significance of histologic type. J Thorac Cardiovasc Surg 109: 130-139, 1995.

10. Ellis FH Jr, Heatley GJ, Krasna MJ, Williamson WA and Balogh K: Esophagogastrectomy for carcinoma of the esophagus and cardia: a comparison of findings and results after standard resection in three consecutive eight-year intervals with improved staging criteria. J Thorac Cardiovasc Surg 113: 836-848, 1997.

11. Isono K, Sato H and Nakayama K: Results of a nationwide study on the three-field lymph node dissection of esophageal cancer. Oncology 48: 411-420, 1991.

12. Ando N, Ozawa S, Kitagawa Y, Shinozawa Y and Kitajima M: Improvement in the results of surgical treatment of advanced squamous esophageal carcinoma during 15 consecutive years. Ann Surgery 232: 225-232, 2000.

13. Altorki N and Skinner D: Should en bloc esophagectomy be the standard of care for esophageal carcinoma? Ann Surg 234: 581-587, 2001.

14. Lerut T, Nafteux P, Moons J, et al: Three-field lymphadenectomy for carcinoma of the esophagus and gastroesophageal junction in 174 R0 resections: impact on staging, disease-free survival, and outcome: a plea for adaptation of TNM classification in upper-half esophageal carcinoma. Ann Surg 240: 962-974, 2004. 
15. Lerut T, Coosemans W, Decker G, et al: Extended surgery for cancer of the esophagus and gastroesophageal junction. J Surg Res 117: 58-63, 2004

16. Altorki NK, Girardi L and Skinner DB: En bloc esophagectomy improves survival for stage III esophageal cancer. J Thorac Cardiovasc Surg 114: 948-956, 1997.

17. Collard JM: Exclusive radical surgery for esophageal adenocarcinoma. Cancer 91: 1098-1104, 2001.

18. Clark GW, Peters JH, Ireland AP, et al: Nodal metastasis and sites of recurrence after en bloc esophagectomy for adenocarcinoma. Ann Thorac Surg 58: 646-654, 1994.

19. Chen G, Wang Z, Liu XY and Liu FY: Recurrence pattern of squamous cell carcinoma in the middle thoracic esophagus after modified Ivor-Lewis esophagectomy. World J Surg 31: 1107-1114, 2007.

20. Nakagawa S, Kanda T, Kosugi S, Ohashi M, Suzuki T and Hatakeyama K: Recurrence pattern of squamous cell carcinoma of the thoracic esophagus after extended radical esophagectomy with three-field lymphadenectomy. J Am Coll Surg 198: 205-211, 2004.

21. Matsubara T, Ueda M, Takahashi T, Nakajima T and Nishi M: Localization of recurrent disease after extended lymph node dissection for carcinoma of the thoracic esophagus. J Am Coll Surg 182: 340-346, 1996.

22. Bhansali MS, Fujita H, Kakegawa T, et al: Pattern of recurrence after extended radical esophagectomy with three-field lymph node dissection for squamous cell carcinoma in the thoracic esophagus. World J Surg 21: 275-281, 1997.

23. Hulscher JB, van Sandick JW, Tijssen JG, Obertop H and van Lanschot JJ: The recurrence pattern of esophageal carcinoma after transhiatal resection. J Am Coll Surg 191: 143-148, 2000

24. Kyriazanos ID, Tachibana M, Shibakita M, et al: Pattern of recurrence after extended esophagectomy for squamous cell carcinoma of the esophagus. Hepatogastroenterology 50: $115-120,2003$.

25. Mariette C, Balon JM, Piessen G, Fabre S, Van Seuningen I and Triboulet JP: Pattern of recurrence following complete resection of esophageal carcinoma and factors predictive of recurrent disease. Cancer 97: 1616-1623, 2003.

26. Akiyama $\mathrm{H}$, Tsurumaru M, Udagawa $\mathrm{H}$ and Kajiyama Y: Radical lymph node dissection for cancer of the thoracic esophagus. Ann Surg 220: 364-373, 1994.

27. Kato H, Watanabe H, Tachimori $\mathrm{Y}$ and Iizuka T: Evaluation of neck lymph node dissection for thoracic esophageal carcinoma. Ann Thorac Surg 51: 931-935, 1991.

28. Altorki N, Kent M, Ferrara C and Port J: Three-field lymph node dissection for squamous cell and adenocarcinoma of the esophagus. Ann Surg 236: 177-183, 2002.

29. Urba SG, Orringer MB, Perez-Tamayo C, Bromberg J and Forastiere A: Concurrent preoperative chemotherapy and radiation therapy in localized esophageal adenocarcinoma. Cancer 69: 285-291, 1992.

30. Walsh TN, Noonan N, Hollywood D, Kelly A, Keeling N and Hennessy TP: A comparison of multimodal therapy and surgery for esophageal adenocarcinoma. N Engl J Med 335: 462-467, 1996.

31. Nygaard K, Hagen S, Hansen HS, et al: Pre-operative radiotherapy prolongs survival in operable esophageal carcinoma: a randomized, multicenter study of pre-operative radiotherapy and chemotherapy. The second Scandinavian trial in esophageal cancer. World J Surg 16: 1104-1110, 1992.

32. Le Prise E, Etienne PL, Meunier B, et al: A randomized study of chemotherapy, radiation therapy, and surgery versus surgery for localized squamous cell carcinoma of the esophagus. Cancer 73: $1779-1784,1994$

33. Apinop C, Puttisak P and Preecha N: A prospective study of combined therapy in esophageal cancer. Hepatogastroenterology 41: 391-393, 1994

34. Bosset JF, Gignoux M, Triboulet JP, et al: Chemoradiotherapy followed by surgery compared with surgery alone in squamous-cell cancer of the esophagus. N Engl J Med 337: 161-167, 1997.

35. Urba SG, Orringer MB, Turrisi A, Iannettoni M, Forastiere A and Strawderman M: Randomized trial of preoperative chemoradiation versus surgery alone in patients with locoregional esophageal carcinoma. J Clin Oncol 19: 305-313, 2001.

36. Lee JL, Park SI, Kim SB, et al: A single institutional phase III trial of preoperative chemotherapy with hyperfractionation radiotherapy plus surgery versus surgery alone for resectable esophageal squamous cell carcinoma. Ann Oncol 15: 947-954, 2004.
37. Burmeister BH, Smithers BM, Gebski V, et al: Surgery alone versus chemoradiotherapy followed by surgery for resectable cancer of the oesophagus: a randomised controlled phase III trial. Lancet Oncol 6: 659-668, 2005.

38. Tepper J, Krasna MJ, Niedzwiecki D, et al: Phase III trial of trimodality therapy with cisplatin, fluorouracil, radiotherapy, and surgery compared with surgery alone for esophageal cancer: CALGB 9781. J Clin Oncol 26: 1086-1092, 2008.

39. Fujiwara Y, Kamikonya N, Inoue T, et al: Chemoradiotherapy for T3 and T4 squamous cell carcinoma of the esophagus using low-dose FP and radiation: A preliminary report. Oncol Rep 14: $1177-1182,2005$.

40. Fujiwara Y, Yoshikawa R, Kamikonya N, et al: Trimodality therapy of esophagectomy plus neoadjuvant chemoradiotherapy improves the survival of clinical stage II/III esophageal squamous cell carcinoma patients. Oncol Rep 28: 446-452, 2012.

41. Sobin LH and Wittekin CH (eds): International Union Against Cancer (UICC). TNM classification of malignant tumors. 5th edition. John Wiley \& Sons, Inc., New York, 1997.

42. Japanese Society for Esophageal Diseases: Guidelines for clinical and pathologic studies on carcinoma of the esophagus. 9th edition. Kanehara \& Co., Ltd., Tokyo, 2001.

43. National Cancer Institute: Cancer Therapy Evaluation Program, Common Terminology Criteria for Adverse Events. Version 3.0. http://ctep.cancer.gov/protocolDevelopment/electronic_applications/docs/ctcaev3.pdf. Accessed August 28, 2012.

44. Muller JM, Erasmi H, Stelzner M, Zieren U and Pichlmaier H: Surgical therapy of oesophageal carcinoma. Br J Surg 77: 845-857, 1990

45. Kakegawa T: Study on rational surgery for thoracic esophageal cancer based on the esophageal lymphatic drainage. In: Annual Report of the Cancer Research Ministry of Health and Welfare 1990, Tokyo: National Cancer Center, pp285-289, 1991 (In Japanese)

46. Iizuka T: Report of 4th Meeting of ISDE TNM. Research Committee. Kyoto, 1992.

47. Watanabe H, Kato H and Tachimori Y: Significance of extended systemic lymph node dissection for thoracic esophageal carcinoma in Japan. Recent Results Cancer Res 155: 123-133, 2000.

48. Ide H (ed): Comprehensive Registry of Esophageal Cancer in Japan $(1998,1999)$ and Long-term Results of Esophagectomy in Japan (1988-1997). 3rd edition. The Japanese Society for Esophageal Disease, Chiba, 2002.

49. Herskovic A, Martz K, al-Sarraf M, et al: Combined chemotherapy and radiotherapy compared with radiotherapy alone in patients with cancer of the esophagus. N Engl J Med 326: 1593-1598, 1992.

50. Minsky BD, Pajak TF, Ginsberg RJ, et al: INT 0123 (Radiation Therapy Oncology Group 94-05) phase III trial of combinedmodality therapy for esophageal cancer: high-dose versus standard-dose radiation therapy. J Clin Oncol 20: 1167-1174, 2002.

51. Yoshikawa R, Nakano Y, Tao L, et al: Hedgehog signal activation in oesophageal cancer patients undergoing neoadjuvant chemoradiotherapy. Br J Cancer 98: 1670-1674, 2008.

52. Igaki H, Tachimori $Y$ and Kato H: Improved survival for patients with upper and/or middle mediastinal lymph node metastasis of squamous cell carcinoma of the lower thoracic esophagus treated with 3-field dissection. Ann Surg 239: 483-490, 2004.

53. Fujita H, Kakegawa T, Yamana $\mathrm{H}$, et al: Mortality and morbidity rates, postoperative course, quality of life, and prognosis after extended radical lymphadenectomy for esophageal cancer. Comparison of three-field lymphadenectomy with two-field lymphadenectomy. Ann Surg 222: 654-662, 1995.

54. Ando N, Kato H, Igaki H, et al: A randomized trial comparing postoperative adjuvant chemotherapy with cisplatin and 5-fluorouracil versus preoperative chemotherapy for localized advanced squamous cell carcinoma of the thoracic esophagus (JCOG9907). Ann Surg Oncol 19: 68-74, 2012

55. Kitagawa Y, Ando N, Nakamura K, Shibata T and Fukuda H: The role of adjuvant chemotherapy for localized squamous cell esophageal cancer: current Japanese standard and the unending role of the drawing board. Ann Surg Oncol 19: 1425-1427, 2012

56. Ajani JA and Swisher SG: Preoperative chemotherapy for localized squamous cell carcinoma of the esophagus? We should go back to the drawing board! Ann Surg Oncol 19: 3-4, 2012. 